\title{
Definitions and criteria: the 2007 amendments to the Mental Health Act 1983
}

\author{
Tim Branton \& Guy Brookes
}

\begin{abstract}
This article deals with the provisions for the lawful detention and compulsory treatment of patients in England and Wales. The 2007 amendments to the Mental Health Act 1983 redefine 'mental disorder' and 'medical treatment' and remove the classifications required for longer-term detention, abolishing the so-called 'treatability test' and introducing a new appropriate-treatment test. 'Learning disability' is brought within the definition of mental disorder but only if 'associated with abnormally aggressive or seriously irresponsible conduct'. The exclusion for promiscuity, other immoral conduct or sexual deviancy is repealed; the exclusion for dependence on alcohol and drugs is retained. The revised definition of 'medical treatment' includes psychological treatment and removes the requirement that treatment is under medical supervision. The basic structure of the 1983 Act is retained. Use of the powers is discretionary. The principles of the Mental Capacity Act 2005 are imported into the decision-making framework through the wording of the Mental Health Act Code of Practice.
\end{abstract}

\section{DECLARATION OF INTEREST}

None.

The Mental Health Act 1983 received Royal Assent on 9 May 1983 and came into force on 30 December 1983. It replaced the Mental Health (Amendment) Act 1982 and repealed much of the Mental Health Act 1959. In England and Wales, only psychiatrists with the longest memories have worked under any other legal framework than the 1983 Act. The longevity of the Act is partly accounted for by the radical and ultimately abortive attempts at reform, from the recommendations of the report of the Richardson committee in 1999 (Department of Health 1999) to the failure of the Mental Health Bill of 2005. The 2007 amendments received Royal Assent on 19 July 2007 and were substantially implemented on 3 November 2008. Although the focus of this article is the changes to definitions and criteria, the Act remains, and should be referred to as, the
Mental Health Act 1983 and the structure and provisions will be familiar.

We will refer to Section 3 when discussing longerterm detention, but the changes to definitions also apply to the Part III equivalent provisions where someone is detained to hospital for assessment and treatment. In addition, the revised definitions also apply at the First-tier Tribunal (Mental Health) (Sections 72 and 73).

\section{The European perspective}

It is important to understand the Mental Health Act 1983 in the European context of the law. The European Convention on Human Rights was drafted following the Second World War and came into effect in 1953. The contents reflect the postwar mood and pre-date by some decades political support for rights of disabled people. However, several articles of the Convention and subsequent European case law are an important influence in shaping definitions within the Mental Health Act: Article 3 prohibits torture or inhumane or degrading treatment or punishment; ${ }^{\dagger}$ and Article 8 provides the right to respect for private and family life. Either of these rights might be infringed by misapplication of mental health legislation or practice but the Article 5 right to liberty and security of person is the right that most directly affects the drafting and application of mental health law (Box 1).

The European Court of Human Rights has developed through case law the definition of

\section{BOX 1 European Convention on Human Rights, Article 5}

5.1 Everyone has the right to liberty and security of person. No one shall be deprived of his liberty save in the following cases and in accordance with a procedure prescribed by law:

(e) the lawful detention of persons for the prevention of the spreading of infectious diseases, of persons of unsound mind, alcoholics or drug addicts or vagrants.
Tim Branton is a consultant psychiatrist of old age. He trained as a general practitioner before training in psychiatry. As Associate Medical Director for Mental Health Legislation for Leeds Partnerships Foundation NHS Trust, he has been responsible for leading the local implementation of the 2007 amendments to the Mental Health Act. Guy Brookes is a consultant psychiatrist working in a crisis resolution and home-treatment team in Leeds Partnerships Foundation NHS Trust. He is also Associate Medical Director for Continuing Professional Development and works with the Andrew Sims Centre to deliver mental health training, including in Mental Health Law. Correspondence $\mathrm{Dr}$ Tim Branton, The Mount, 44 Hyde Terrace, Leeds LS2 9LN, UK. Email: Tim.Branton@leedspft.nhs.uk.

${ }^{\dagger}$ For an update on Article 3 case law see Curtice, pp. 199-206, this issue. For discussion in Advances of the Human Rights Act 1998, which incorporates into UK domestic law most of the European Convention on Human Rights, see: Curtice M, Sandford J (2009) Article 2 of the Human Rights Act 1998 and the treatment of prisoners, 15: 444-450; Curtice M (2008) Article 3 of the Human Rights Act 1998: implications for clinical practice, 14: 389-397; Curtice M, Sandford J (2010) Article 3 of the Human Rights Act 1998 and the treatment of prisoners , 16 105-114; Curtice M (2009) Article 8 of the Human Rights Act 1998: implications for clinical practice, 15: 23-31. 
'unsound mind' to provide a more applicable test for 'unsound mind'. The seminal case Winterwerp v. Netherlands (1979) established the criteria that Member States must apply in the definition of mental disorder:

\begin{abstract}
the individual concerned should not be deprived of his liberty unless he has been reliably shown to be of 'unsound mind'. The very nature of what has to be established before the competent national authority - that is, a true mental disorder - calls for objective medical expertise. Further, the mental disorder must be of a kind or degree warranting compulsory confinement. What is more, the validity of continued confinement depends upon the persistence of such a disorder.
\end{abstract}

The language of Winterwerp at paragraph 39 reflects the provisions of the 1959 Act that persisted in the 1983 Act.

The Human Rights Act 1998, which came into force in October 2000, provides a remedy in the domestic courts for those who believe their Convention rights have been infringed, places a duty on public authorities to act in accordance with the Convention, and obliges judges to interpret

BOX 2 Code of Practice guiding principles

\section{Purpose principle}

- Minimising the undesirable effects of mental disorder

- Maximising safety and well-being (mental and physical)

- Promoting recovery

- Protecting other people from harm

Least restriction principle

- Minimising the restrictions imposed on the patient's liberty

- Having regard to the purpose for which the restrictions are imposed

Respect principle

- Recognising and respecting needs including race, religion, culture, gender, age, sexual orientation and any disability

- Considering the patient's views, wishes and feelings (whether expressed at the time or in advance)

- Following those wishes wherever practicable

- Consistency with the purpose of the decision

- There must be no unlawful discrimination

Participation principle

- Involving patients in planning, developing and reviewing their treatment and care

- Involving carers, family members and other people who have an interest in the patient's welfare

Effectiveness, efficiency and equity principle

- Using resources effectively, efficiently and equitably

- Meeting the needs of the patient

- Achieving the purpose for which the decision was taken

(Department of Health 2008a) the law in-line with the Convention. Where it is not possible to interpret the law in-line with the Convention, the court must make a declaration of incompatibility. This has already happened to the Mental Health Act following $R$ (on the application of H) v. Mental Health Review Tribunal North $\mathcal{E}$ East London Region. The Secretary of State for Health introduced a remedial order that reversed the burden of proof in tribunal hearings from the patient to the hospital. The effect of the remedial order is that the hospital has to make the case for criteria for continued detention being met rather than the patient having to make the case for the criteria not being met.

\section{The Code of Practice}

The 1983 Act is accompanied by a new Code of Practice and a Reference Guide (Department of Health 2008a; 2008b) that replaces the Memorandum (Department of Health \& Welsh Office 1998). It is important to note that the 2007 amendments incorporate $R$ (on the application of Munjaz) v. Ashworth Hospital Authority [2005] at Section 118(2D), stating that "persons performing functions in relation to the Act 'shall have regard to the code'. Thus, this article will make frequent references to the Code of Practice as the interpretations of the Code not only have authority but shed light on the legislative intent of the amendments.

The Code of Practice introduces a 'Statement of guiding principles' to help with the application of the Act. Decisions must be lawful and in-line with good professional practice - they are informed by the principles but not determined by them; the principles incorporate the decision-making framework of the Mental Capacity Act 2005. Although the Code states that the weight given to each principle will be determined by the context in which the decision is taken, the purpose principle is clearly meant to take priority (Box 2).

\section{Criteria for detention and compulsory treatment}

The criteria can be read as a series of tests that the patient has to 'pass' for detention or compulsion. These are:

- the mental disorder test

- the appropriateness test

- the health and safety or protection test

- a new appropriate treatment test (for longerterm detention).

The 2007 amendments operate together to influence liability to detention or compulsory treatment but will be discussed individually. 


\section{A single definition of mental disorder}

The purpose of the Mental Health Act 1983 is set out at Section 1(1) and is unamended:

The provisions of this Act shall have effect with respect to the reception, care and treatment of mentally disordered patients, the management of their property and other related matters.

Since the introduction of the Mental Capacity Act 2005 the phrase 'management of their property and other related matters' is somewhat redundant as the relevant provisions have been removed.

Part I of the 1983 Act continues with the definition of mental disorder at Section 1(2):

'mental disorder' means any disorder or disability of the mind; and 'mentally disordered' shall be construed accordingly.

The definition has been eviscerated by the removal of the classifications of mental disorder. The flexibility of this definition allows it to be Winterwerp-compatible and keep pace with the evolution of psychiatric terminology.

The Code of Practice includes a list of disorders that could fall within the definition of mental disorder (Box 3) and notes that this list 'is not exhaustive'; among clinicians, this list leads to raised eyebrows and heated debate. It must be noted that all of the disorders on the list (with the exception of the non-organic sexual disorders) could have been construed as a mental disorder before the 2007 amendments. In addition, the 'mental disorder' test is only one of the criteria that must be satisfied for detention or compulsion. So although, for instance, anxiety is a mental disorder in the meaning of the Act, it would be necessary to demonstrate applicability of the appropriateness and health and safety tests (for Section 2) and the 'treatability test' (for longer-term detention or compulsion).

\section{The removal of the classifications of mental disorders}

The four categories of mental disorder required for longer-term detention (mental illness, mental impairment, severe mental illness and psychopathic disorder) are removed from the 1983 Act. Learning disability is defined in Section 1(4) as 'a state of arrested or incomplete development of the mind which includes significant impairment of intelligence and social functioning'. For Section 3, learning disability cannot be considered to be a mental disorder unless 'associated with abnormally aggressive or seriously irresponsible conduct'.

Abnormally aggressive or seriously irresponsible conduct is not defined in the Act. The Code of Practice suggests that factors to take into account when assessing whether behaviour should be categorised as abnormally aggressive may include:
- how persistent and severe the behaviour has been

- whether it has occurred without a specific trigger or seems out of proportion to the circumstances

- whether, and to what degree, it has resulted in harm or distress to other people or damage to property

- if it has not occurred recently, how likely it is to recur

- how common similar behaviour is in the population generally.

For seriously irresponsible behaviour, relevant factors may include:

- whether behaviour has occurred that suggests a disregard or an inadequate regard for its serious or dangerous consequences

- how recently has such behaviour occurred and how persistent it has been

- how seriously detrimental to the patient or to others the consequences were or might have been

- whether, and to what degree, it has resulted in harm to the patient or their interests, or in harm to other people or to damage to property

- if it has not occurred recently, how likely it is to recur.

Irresponsible conduct cannot be construed to be exposure to risk by, for instance, living in unsuitable accommodation. In Re F (Mental Health Act: Guardianship) [2000] a 17-year-old patient with learning disability wanted to return home where there was a likelihood of neglect and sexual exploitation. The Court of Appeal held that this was not 'irresponsible conduct'.

BOX 3 Clinically recognised conditions that could fall within the 1983 Act's definition of mental disorder

- Affective disorders, such as depression and bipolar disorder

- Schizophrenia and delusional disorders

- Neurotic, stress-related and somatoform disorders, such as anxiety, phobic disorders, obsessive compulsive disorders, post-traumatic stress disorder and hypochondriacal disorders

- Organic mental disorders such as dementia and delirium (however caused)

- Personality and behavioural changes caused by brain injury or damage (however acquired)

- Personality disorders

- Mental and behavioural disorders caused by psychoactive substance use

- Eating disorders, non-organic sleep disorders and non-organic sexual disorders

- Learning disabilities

- Autistic spectrum disorders (including Asperger syndrome)

- Behavioural and emotional disorders of children and adolescents.

(Department of Health 2008a) 
The removal of the exclusion for deviant sexual conduct and retention of exclusion for drug and alcohol dependence

The exclusion for promiscuity, other immoral conduct or sexual deviancy is repealed. This has the intent and effect of bringing paedophilia within the definition of mental disorder.

The exclusion for dependence on alcohol and drugs is retained. As can be seen from Article 5.1(e) of the European Convention on Human Rights (Box 1), European law allows the detention of people with addictions. The draft Mental Health Bill 2004 sought to bring addictions into the definition of mental disorder and was heavily criticised on the grounds that substance use and dependence forms part of a spectrum of normal behaviour and that the threat of compulsion might lead dependent people to delay seeking help.

The House of Lords amended the Bill to provide that a person should not be considered to have a mental disorder solely on the grounds of (a) his substance misuse (including dependence on alcohol or drugs); (b) his sexual identity or orientation; (c) his commission or likely commission of illegal or disorderly acts; or (d) his cultural, religious or political beliefs. This amendment was overturned in the Commons Public Bill Committee in favour of a single clause stating that dependence on alcohol or drugs is not considered to be a mental disorder or disability of the mind.

The House of Lords and House of Commons Joint Committee on Human Rights did not object to paedophilia being considered a mental disorder but they objected to the removal of the sexual conduct exclusion because it would allow fetishism, masochism and gender-identity disorders to be construed as mental disorders (House of Lords and House of Commons Joint Committee on Human Rights 2007a, b). The Government's response was that as well as paedophilia, 'clinically significant' paraphilias should also be construed as mental disorders and it went ahead with the repeal of the exclusion. The legal advisors to a patient detained by virtue of their clinically significant paraphilia might wish to consider a European Convention Article 8 challenge.

The Code of Practice clarifies that the mental health complications of substance misuse, the effects of withdrawal, and intoxication can all be considered to be mental disorders. The lawful detention for intoxication alone is made unlikely in the context of the other 'tests'.

\section{Appropriateness test}

The provisions of Section 2 allow detention for assessment or assessment followed by medical treatment of a patient if 'he is suffering from mental disorder of a nature or degree which warrants the detention of the patient in a hospital'. The provisions of Section 3 are that the patient 'is suffering from a mental disorder of a nature or degree which makes it appropriate for him to receive medical treatment in a hospital'. In $R$ v Kirklees $M B C$ ex parte $C$ [1993], Lord Justice Lloyd clarified that 'is suffering from' can be construed to mean 'appears to be suffering from', stating: 'Any other construction would unnecessarily emasculate the beneficial power under s 2' (cited in Bartlett 2007: p. 127) .'Suffering' is not taken to mean an unpleasant subjective experience in the ordinary sense of the word but in the medical sense of 'experiencing'.

Psychiatrists can struggle with the legal terms 'nature' or 'degree' becausein mostclinical situations, the team is concerned about a combination of these factors. Justice Popplewell considers these terms in $R$ v. Mental Health Review Tribunal for the South Thames Region ex parte Smith (1999). The patient in this case had schizophrenia that relapsed when the patient discontinued medication and was asymptomatic at the time of the tribunal. The responsible clinician gave evidence that the patient had a mental disorder of a nature but not of a degree to make detention for treatment appropriate. Justice Popplewell agreed that the terms may be used disjunctively. 'Nature' is held to refer to the condition itself, its chronicity, prognosis and what is known about the patient's response to treatment. 'Degree' refers to the current symptoms and manifestations. The case also establishes that a patient can be lawfully detained while asymptomatic if the nature of their condition is one of rapid relapse when medication is discontinued after discharge from compulsion.

The term 'warrants' for Section 2 needs to be read in conjunction with the Code of Practice at paragraph 4.4:

Before it is decided that admission to hospital is necessary, consideration must be given to whether there are alternative means of providing the care and treatment which the patient requires. This includes consideration of whether there might be other effective forms of care or treatment which the patient would be willing to accept, and of whether guardianship would be appropriate instead.

Alternatives to detention refer not only to alternative services but also to alternative legal provisions such as informal admission or where the proposed care and treatment would be lawful by virtue of the Mental Capacity Act. These alternatives are not only desirable but if available render Mental Health Act detention unlawful.

The term 'makes it appropriate' for Section 3 of the 1983 Act is read with Section 3(2)(c) that 'it 
cannot be provided unless he is detained under this section' and also with the considerations of alternative service and legal provision as outlined for Section 2.

\section{The health and safety and the protection of others tests}

Applying the 'health' test is an area that gives rise to clinical dilemmas. Suppose that capacitous patients decide to reject treatment advice and choose a course of action that is hazardous to their health. Is it appropriate that psychiatrists use a power that cannot be used against capacitous patients subject to the same hazard with no mental disorder? Even for patients with impaired decision-making capacity, it is not straightforward to decide when to use the Mental Health Act. Determining this threshold is a matter of clinical judgement but the Code of Practice at paragraph 4.6 includes considerations of the patient's mental health as well as physical health and also that detention can be to prevent future deterioration of mental or physical health (following $R \mathrm{v}$. Mental Health Review Tribunal for the South Thames Region ex parte Smith (1999)). Safety of the patient refers to the risk of accidental or deliberate harm secondary to the mental disorder.

When considering harm to others, practitioners should consider the nature of the risk together with the likelihood and severity of the threat. Protection of others refers not only to the threat of physical harm but the experience of emotional distress resulting from the mental disorder (Code of Practice at paragraph 4.8). The Code also recognises that risks to self and others can coexist. The law does not consider an unborn child to be a person; practitioners could, however, consider applying the 'health test' to a pregnant patient with mental disorder compromising the safety of her unborn child.

\section{The new appropriate treatment test}

To understand the changes to the treatability test it is worth examining Reid v. Secretary of State for Scotland [1999]. . This case is important because the Law Lords consider what constitutes medical treatment and whether it can support the detention of an individual with psychopathic disorder who is not suitable for psychiatric treatment. The case demonstrates that 'preventive detention' may have been lawful in England and Wales before the 2007 amendments. The Law Lords were clearly dissatisfied with the way the treatability test worked and the concluding comments of Lord Hutton called for Parliament to review the law that 'the balancing of the protection of the public as against

\section{BOX 4 Reid v. Secretary of State for Scotland [1999]}

In 1967, Reid stabbed a woman to death. He was convicted of culpable homicide. Reid was found to have mental deficiency and was made subject to a detention order and a restriction order without limit of time. He was subsequently diagnosed as having a psychopathic personality. In 1985 he was moved to another hospital, but in the following year he was convicted of an assault on an 8-year-old girl, sentenced to 3 months' imprisonment and, after his release from prison, recalled to the State Hospital. He applied for discharge because he had a persistent mental disorder 'manifested only by abnormally aggressive or serious irresponsible conduct', which was not treatable. The sheriff refused his application. Reid appealed and the Inner House reversed the decision of the sheriff, holding that there was no evidence that the continued detention of Reid was likely to 'alleviate or prevent a deterioration of his condition' within the meaning of Section 17(1)(a)(i) of the Mental Health (Scotland) Act 1984.

The Secretary of State for Scotland appealed. The Law Lords concluded that:

1 that the treatability of a patient was an inherent part of the 'appropriateness' test under Section 64(1)(a) of the Mental Health (Scotland) Act 1984;

2 a sheriff was bound to grant an application for discharge under Section 64(1)(a) where a patient had a persistent mental disorder 'manifested only by abnormally aggressive or serious irresponsible conduct' if treatment was not likely to 'alleviate or prevent a deterioration of his condition':

3 there was agreement among experts that medical treatment was not likely to alleviate Reid's condition;

4 the treatability test was wider than psychiatric treatment;

5 the structured and controlled environment of the hospital could be considered in relation to the treatability test.

the claim of a psychopath convicted many years ago that he should not continue to be detained in hospital when medical treatment will not improve his condition, is an issue for Parliament to decide and not for judges' (Box 4).

The first effect of the 2007 amendments is the removal of the classifications for longer-term detention and treatment. This means that the 'treatability test' applies to all forms of detention and not just to mental impairment and psychopathic disorder. This goes considerably further than Article 5.1(e) of the European Convention on Human Rights, which does not place an obligation to treat on authorities detaining 'persons of unsound mind'. The Code of Practice reinforces the message 'no detention without treatment' at paragraph 6.7.

The new 'appropriate treatment' test states that 'appropriate treatment is available for the patient'. Section 3(4) of the 1983 Act defines appropriate treatment as "medical treatment which is appropriate in his case, taking into account the nature and degree of the mental disorder and all other circumstances of his case'. A practical consequence for clinicians of the wording at Section $3(2)(d)$ is that when making a recommendation for detention under Section 3 the doctor will have to specify a hospital or hospitals where appropriate treatment is available and to which the patient could be admitted.
${ }^{\dagger}$ New legislation that has since been enacted in Scotland is discussed in Lyons D (2008) New mental health legislation in Scotland. Advances in Psychiatric Treatment 14: 89-97. Ed. 
MCO answers

$\begin{array}{lllll}1 b & 2 c & 3 b & 4 b & 5 a\end{array}$
The amended Section 145 defines medical treatment as "psychological intervention and specialist mental health habilitation, rehabilitation and care ... medical treatment the purpose of which is to alleviate, or prevent a worsening of, the disorder or one or more of its symptoms or manifestations'. The effect of the amendment is to replace 'likely' with 'purpose' and 'condition' with 'disorder' and 'symptoms or manifestations'. The revised definition of medical treatment adds psychological treatment and removes the requirement for medical treatment to be supervised by the registered medical practitioner in charge of the case.

'Purpose' is not the same as 'likelihood'. The Code of Practice at paragraph 6.4 endorses this distinction:

Medical treatment may be for the purpose of alleviating, or preventing a worsening of, a mental disorder even though it cannot be shown in advance that any particular effect is likely to be achieved.

In ordinary language, 'purpose' would appear to be a less stringent test than 'likelihood' as the likelihood test asked doctors to base their opinion on a prediction rather than their intent. The amended wording is probably a more honest statement of the therapeutic goals of compulsion.

The definition of appropriateness is clarified at paragraph 6.12:

Medical treatment need not be the most appropriate treatment that could ideally be made available. Nor does it need to address every aspect of the person's disorder. But the medical treatment available at any time must be an appropriate response to the patient's condition and situation.

The Code of Practice at paragraphs 6.16-6.19 makes it clear that neither therapeutic nihilism nor unwillingness on the part of the patient is a justification for avoiding compulsion:

an indication of unwillingness to co-operate with treatment generally, or with a specific aspect of treatment, does not make such treatment inappropriate...

$[P]$ sychological therapies and other forms of medical treatments which, to be effective, require the patient's co-operation are not automatically inappropriate simply because a patient does not currently wish to engage with them..

There may be patients whose particular circumstances mean that treatment may be appropriate even though it consists only of nursing and specialist day-to-day care under the clinical supervision of an approved clinician, in a safe and secure therapeutic environment with a structured regime.

The treatability test set up a perverse incentive for patients with psychopathic disorder to refuse to participate in treatment. Thus, a patient might appeal on the grounds that he was not participating in treatment. Such an appeal could
B0X 5 Further reading

Bowen P (2007) Blackstone's Guide to the Mental Health Act 2007. Oxford University Press.

Hewitt D (2007) Re-considering the Mental Health Bill. The view of the Parliamentary Human Rights Committee. Journal of Mental Health Law May: 57-71.

Jones R (2008) Mental Health Act Manual (11th edn). Sweet and Maxwell.

not be successful now because the treatment would simply have to be available. More significantly, the 'loophole' perceived by politicians that meant that patients with dangerous and severe personality disorders may not have been liable for detention has been closed. Clinicians may have clinical, ethical and pragmatic objections to detaining such individuals but there are fewer legal impediments to compulsion.

\section{The likely impact of the changes to definitions and criteria}

This article has set out how the 2007 amendments affect the definitions and criteria within the Mental Health Act 1983 (further reading on the topic is listed in Box 5). Throughout the article we have given evidence that many of the changes are being established by judicial interpretation of the previous statute or that perceived changes to definitions (for instance the extended definition of mental disorder in the Code of Practice) do not represent any statutory change. A trite conclusion would be plus ça change... However, other provisions within the amendments, such as changes to professional roles, might act synergistically with changes to definitions. This could lead to new services, offering compulsory treatment to individuals hitherto unlikely to be held liable to detention (Box 6).

\section{Acknowledgement}

We thank Tony Zigmond for his advice on the preparation of this article.

\section{References}

Bartlett P, Sandland R (2007) Mental Health Law: Policy and Practice (3rd edn). Oxford University Press.

Department of Health (1999) Review of the Mental Health Act 1983: Report of the Expert Committee. Department of Health.

Department of Health (2008a) Mental Health Act 1983 Code of Practice. TSO (The Stationery Office)

Department of Health (2008b) Reference Guide to the Mental Health Act 1983. TSO (The Stationery Office).

Department of Health \& Welsh Office (1998) Mental Health Act 1983 Memorandum on Parts I to VI, VIII and X. TSO (The Stationery Office). 
BOX 6 Case vignettes: practical questions on the 2007 amendments

1 A 23-year-old woman presents to the accident and emergency department reporting that she has taken 25 paracetamol tablets. She is sullen and uncooperative, ambivalent about her survival and does not disclose any further ideas of self-harm.

What are the options for the lawful investigation and treatment of this patient? Have these changed following the 2007 amendments?

2 In 1967, Clatworthy was convicted of two offences of indecent assault. He was made the subject of a hospital order and a restriction order on the grounds that he was experiencing a psychopathic disorder. After the restriction order expired he applied to a mental health review tribunal for consideration of his case. The tribunal heard from medical experts that his problem was one of sexual deviancy, which was not a 'mental disorder' in the meaning of the Mental Health Act 1983, Section 1(3). There was no evidence of psychotic illness or that he was abnormally aggressive or seriously irresponsible. The tribunal disagreed, holding that Clatworthy continued to have a psychopathic disorder of a nature or degree that made it appropriate for him to be detained in hospital for medical treatment. Clatworthy sought judicial review of this decision ( $R$ v. Mental Health Review Tribunal, ex parte Clatworthy [1985]).

How would the tribunal deal with this now? What arguments could Clatworthy's appointed representative advance in support of discharge by the tribunal?

3 A 25-year-old patient with anorexia nervosa has been admitted for assessment under Section 2 to the local psychiatric unit. She is now coming to the end of the 28-day period. She is dangerously underweight and requires nasogastric feeding, specialist monitoring and psychological therapy. The responsible clinician believes that such treatment should be provided at a tertiary referral centre and is concerned about whether a recommendation for detention for treatment at the local hospital will be lawful.

Can treatment be given under the new appropriate treatment test? How would the tribunal deal with an appeal if Section 3 went ahead?

4 A convicted paedophile with a diagnosis of antisocial personality disorder is approaching the end of his sentence. There is concern about his risk of recidivism. A hospital for treatment of sex offenders is asked to review the prisoner A psychologist, who is an approved clinician, offers admission for cognitive-behavioural therapy. The patient refuses to consider admission or therapy.

Is treatment appropriate? Is treatment available? Is detention to hospital for treatment lawful? What would be the role of a medical practitioner in these circumstances?
House of Lords and House of Commons Joint Committee on Human Rights (2007a) Legislative Scrutiny. Mental Health Bill. Fourth Report of Session 2006-07 (HL Paper 40/HC 288). TSO (The Stationery Office).

House of Lords and House of Commons Joint Committee on Human Rights (2007b) Legislative Scrutiny. Seventh Progress Report. Fifteenth Report of Session 2006-07. Drawing Special Attention to: Mental Health Bill (HL Paper 112/HC 555). TSO (The Stationery Office).

$R$ v. Kirklees MBC ex parte C [1993] 2 FLR 187.

R v. Mental Health Review Tribunal, ex parte Clatworthy [1985] 3 All ER 699.
$R v$. Mental Health Review Tribunal for the South Thames Region ex parte Smith (1999) 47 BMLR 104

$R$ (on the application of H) v. Mental Health Review Tribunal North \& East London Region [2001] EWCA Civ 415

$R$ (on the application of Munjaz) v. Ashworth Hospital Authority [2005] UKHL 58.

Re F (Mental Health Act: Guardianship) [2000] 1 FLR 192.

Reid v. Secretary of State for Scotland [1999] 1 All ER 481

Winterwerp v. Netherlands (1979) 2 EHRR 387
MCOs

Select the single best option for each question stem

1 In the Mental Health Act 1983, mental disorder:

a has no definition

b includes learning disability

c excludes uncomplicated intoxication

$\mathrm{d}$ is sufficient grounds for detention

e excludes paedophilia.

\section{A patient cannot be detained just} because of:

a risks consequent on acute drug or alcohol intoxication

b risk of relapse if the patient refuses to take medication but is currently asymptomatic

c alcohol dependence

d self-neglect in dementia e Asperger syndrome without abnormally aggressive or seriously irresponsible conduct.

\section{Medical treatment under the Mental} Health Act 1983:

a excludes psychological treatment

b provides that a patient can be lawfully detained even if taking no prescribed medication or not engaged in a psychological treatment plan

c cannot include a bath

$\mathrm{d}$ provides that the approved clinician for medical treatment must be able to predict a reasonable chance of success for a proposed treatment

e for longer-term detention provides that the recommending doctor does not need to specify where appropriate treatment is available.

4 The Code of Practice:

a is a voluntary code illustrating best practice b sets out important principles that are not included in the statute

c offers advice to patients

$\mathrm{d}$ lists all of the conditions that may be considered a mental disorder

e states that the purpose principle can be ignored in pursuit of the least restrictive option.

5 The European Convention on Human Rights:

a allows for the lawful detention of those of unsound mind

b gives a definition of unsound mind

c exempts treatment in a psychiatric hospital from challenge under Article 3

d prohibits the detention of addicts

e can be varied by the application of the Human Rights Act 1998 